\title{
Inventory Strategy of Dual-Channel Supply Chain from Manufacturer's Perspective
}

\author{
Xie Fengqin*, Nie Qixuan, Yu Hongfei \\ College of Transportation, Shandong University of Science and Technology, Qingdao, China \\ Email address: \\ chilias22@163.com (Xie Fengqin),609362504@qq.com (Nie Qixuan), yuhongfeiqing@qq.com (Yu Hongfei) \\ ${ }^{*}$ Corresponding author
}

To cite this article:

Xie Fengqin, Nie Qixuan, Yu Hongfei. Inventory Strategy of Dual-Channel Supply Chain from Manufacturer's Perspective. International Journal of Management and Fuzzy Systems. Vol. 4, No. 2, 2018, pp. 29-34. doi: 10.11648/j.ijmfs.20180402.14

Received: July 8, 2018; Accepted: July 17, 2018; Published: August 24, 2018

\begin{abstract}
Compared with the traditional retail channel, the online channel has advantages such as wide coverage, low cost and small time limit. Manufacturers with dual channels can increase market share and reduce operating costs. However, the incoordination between channels and the lack of management methods make it difficult to implement the dual-channel supply chain. The supply chain which contains both offline and online sales channels has gradually become an important part of the supply chain research. The inventory management is an important factor influencing enterprise operating cost and supply chain efficiency. As there are many uncertain factors in the supply chain system, inventory management becomes one of the difficulties that manufacturing enterprises face when expanding the online channel. Different from the traditional supply chain inventory control, the dual-channel supply chain inventory management has its own characteristics. From the perspective of manufacturing enterprises, this paper takes the dual-channel supply chain as the research object. The profit models were established under the independent inventory strategy, centralized inventory strategy and a strategy where the online channel is outsourced to a third party. The optimal inventory and maximum profit under different operation modes are solved and compared with each other through numerical simulation analysis. The study provide guidance for inventory management of manufacturing enterprises to reduce operating costs and improve the efficiency of supply chain.
\end{abstract}

Keywords: Dual-Channel Supply Chain, Inventory Strategy, Third Party

\section{Introduction}

With the rapid development of e-commerce, more and more manufacturing enterprises set up online channels on the basis of traditional retail channels. The supply chain which contains both offline and online sales channels has gradually become an important part of the supply chain research. Some scholars have studied the price competition and coordination of the dual-channel supply chain. Hua's [1] analysis showed that the delivery period has a strong impact on the pricing strategies and profits of manufacturers and retailers. Ryan et al. [2] compared and analyzed the balance solution and integration system scheme of the coordination dual-channel supply chain system, and proposed the scheme of sharing revenue and loss. Li et al. [3] established the Nash price balance problem model in the two-channel supply chain, and verified the impact of risk aversion index on decision-making under different parameter environments. Tsay's [4] research results show that the introduction of direct channel when the supplier to the retailer's wholesale prices if changed accordingly, will not be the interests of the damage to the retailers. Mukhopadhyay et al. [5] studied the optimal contract design of dual-channel supply chain under information asymmetry. Dumrongsiri [6] takes into account the consumer utility demand function of price and customer service perception, and constructs the model of manufacturer leading retailer following. The research related to the dual-channel inventory strategy studied in this paper is as follows: Chiangab's [7] model of the users are divided into two types, if out of stock in a channel with customers will be 
transferred to another channel, in the customer's demand under the condition of random compares the various strategic cost analysis. Geng et al. [8] solved the game equilibrium between the production capacity constraint and the unconstrained supply chain by taking into account the two-channel inventory decision influenced by the production capacity factor. Yao [9] analyzed the optimal inventory levels of physical stores and electronic stores based on different inventory strategies and compared the applicability of different strategies. Takahashi et al. [10] designed an improved inventory control strategy by introducing production and distribution costs, and verified the effectiveness of the proposed strategy with Markova analysis. Ellie et al. [11] considered the dual channel inventory allocation problem in the transit warehouse distribution center and established the cost model under the service level constraint.

From the point of view of manufacturers who have both offline and online sales channels, three inventory strategies are put forward: (1) independent inventory strategy; (2) centralized inventory strategy; (3) online channel outsourcing strategy. By establishing the profit model under these three different strategies, the optimal inventory and maximum profit are solved. After that, the numerical simulation analysis is carried out.

\section{The Model}

In order to explore the optimal inventory strategy of dual-channel supply chain inventory system, this section constructed the dual-channel supply chain inventory model under different strategy. The model takes profit maximization as the objective function and inventory level as the decision variable. The dual channel supply chain is described through demand rate, production cost, sales price, inventory holding cost, shortage cost and other parameters.

To simplify the model, this paper assumes that the two-channel supply chain system consists of one manufacturer and one offline retailer [12], and the information of channel members is completely symmetric. The manufacturer is the core enterprise in the dual-channel supply chain and it possesses the online sales channel. The research period is the single sales period, and there is no replenishment in the sales period. The online channel sales the same single product as the offline channel. The production $\operatorname{cost} c$, wholesale price $w$, online price $p_{e}$ and offline price $p_{r}$ of the product are all exogenous variables [13] $\left(c<w<p_{e}<p_{r}\right)$. Both manufacturers and retailers have fixed holding costs when holding inventory $\left(a_{e}, a_{r}\right)$. And the variable holding cost $\left(b_{e}, b_{r}\right)$ is linearly related to the initial inventory. Other parameter notations are shown in Table 1.

Table 1. List of notations.

\begin{tabular}{ll}
\hline List of notations & \\
\hline$X, Y$ & market demand in online channel/offline channel \\
$F(x), G(y)$ & cumulative distribution function of demand in online channel/offline channel \\
$s_{e}, s_{r}$ & unit shortage cost for online channel/offline channel \\
$t_{e}$ & unit distribution cost for online channel \\
$t_{r}$ & unit cost for the manufacture distribute for the retailer \\
$v$ & unit salvage value \\
$Q_{e}, Q_{r}$ & order quantity for online channel/offline channel \\
$\pi_{e}^{i}, \pi_{r}^{i}$ & profit of online channel/offline channel under strategy \\
\hline
\end{tabular}

\subsection{Independent Inventory Strategy}

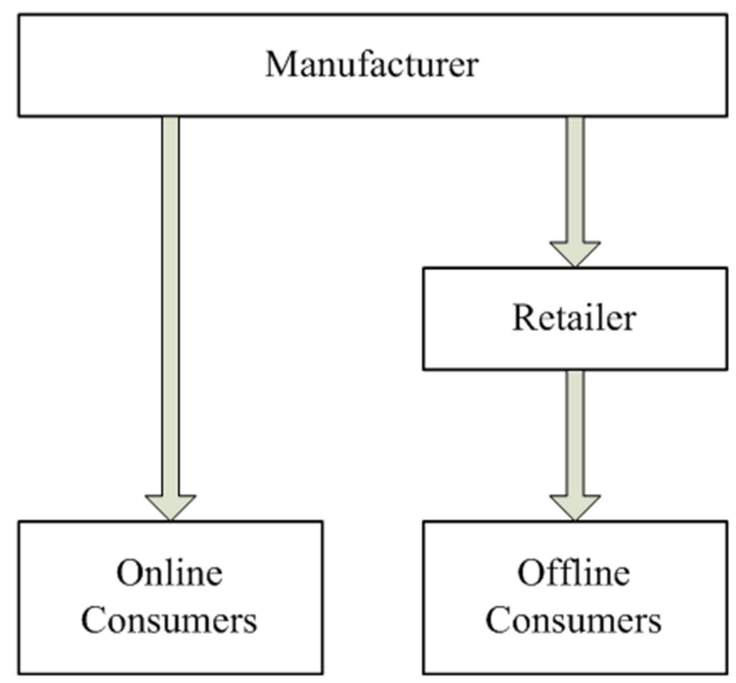

Figure 1. Independent inventory strategy.
Under the independent inventory model, the manufacturer and the retailer make inventory decisions independently and hold their own inventory respectively. The manufacturer's inventory is used to meet the needs of online channel and the manufacture distribute the customers by itself (Figure 1). The manufacturer supplies $Q_{r}$ to the downstream retailer at the beginning of the sales period. This part of the inventory is held by the retailer and is used to meet demand from offline channels. The retailer will not replenish during the sales period and the unit shortage cost is $s_{r}$.

In this case, the manufacture's revenue includes the sales and wholesale revenue. And when the demand is less than the inventory level, the manufacture will get salvage value. Its costs include production costs and inventory costs. And when the inventory level can't meet the market demand, it will cause shortage cost. Similarly, the retailer's revenue includes the sales revenue and the salvage value. And the costs consist of wholesale, inventory and shortage. Therefore, the expected profits of manufacture and retailer are as follows: 


$$
\begin{aligned}
E\left[\pi_{e}^{1}\right]= & p_{e} \cdot E \min \left(Q_{e}, X\right)+w \cdot Q_{r}+v \cdot E \max \left(Q_{e}-X, 0\right)-c \cdot\left(Q_{e}+Q_{r}\right)-\left(a_{e}+b_{e} \cdot Q_{e}\right) \\
- & t_{e} \cdot E \min \left(Q_{e}, X\right)-s_{e} \cdot E \max \left(X-Q_{e}, 0\right) \\
E\left[\pi_{r}^{1}\right] & =p_{r} \cdot E \min \left(Q_{r}, Y\right)+v \cdot E \max \left(Q_{r}-Y, 0\right)-w \cdot Q_{r}-\left(a_{r}+b_{r} \cdot Q_{r}\right) \\
& -s_{r} \cdot E \max \left(Y-Q_{r}, 0\right)
\end{aligned}
$$

The optimal order quantity for the manufacture and the retailer stores are as follows:

$$
\begin{gathered}
Q_{e}^{*}=F^{-1}\left(\frac{p_{e}-t_{e}+s_{e}-c-b_{e}}{p_{e}-t_{e}+s_{e}-v}\right) \\
Q_{r}^{*}=G^{-1}\left(\frac{p_{r}+s_{r}-w-b_{r}}{p_{r}+s_{r}-v}\right)
\end{gathered}
$$

\subsection{Centralized Inventory Strategy}

The manufacturer will centralize the management of its own inventory in online channel and retailers' inventory in offline channel. The manufacturer conducts production in accordance with the retailer's orders and forecasts of the market demand during the sales period. And this part of the inventory is held by the manufacturer. When there are new customer orders, they will be delivered by the manufacturer. The retailer will pay $t_{r}$ for the delivery per unit of production. (Figure 2)

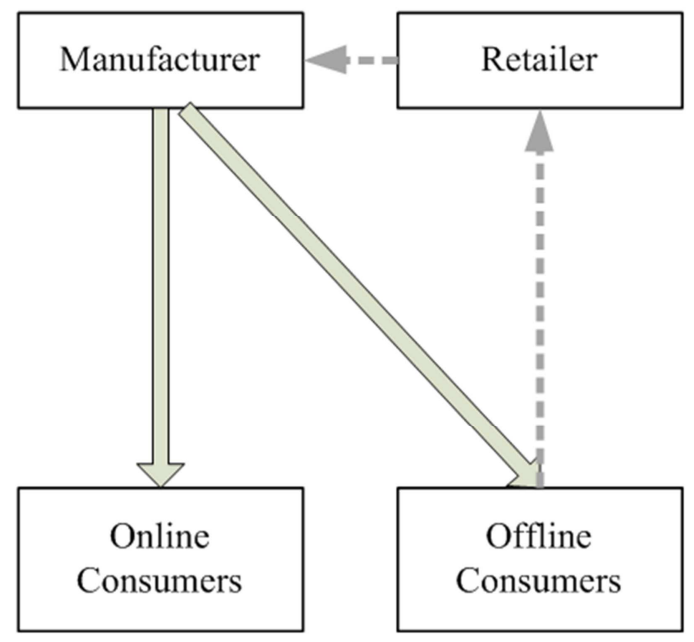

Figure 2. Centralized inventory strategy.

Under this strategy, the expected profits of manufacture and retailer are as follows:

$$
\begin{aligned}
& E\left[\pi_{e}^{2}\right]=p_{e} \cdot E \min \left(Q_{e}, X\right)+w \cdot Q_{r}+v \cdot E \max \left(Q_{e}-X, 0\right)+v \cdot E \max \left(Q_{r}-Y, 0\right)-c \cdot\left(Q_{e}+Q_{r}\right) \\
&-\left[a_{e}+b_{e} \cdot\left(Q_{e}+Q_{r}\right)\right]-t_{e} \cdot E \min \left(Q_{e}, X\right)+t_{r} \cdot E \min \left(Q_{r}, Y\right)-s_{e} \cdot E \max \left(X-Q_{e}, 0\right) \\
& E\left[\pi_{r}^{2}\right]=p_{r} \cdot E \min \left(Q_{r}, Y\right)-w \cdot Q_{r}-t_{r} \cdot E \min \left(Q_{r}, Y\right)-s_{r} \cdot E \max \left(Y-Q_{r}, 0\right)
\end{aligned}
$$

The optimal order quantity for the manufacture and the retailer stores are as follows:

$$
\begin{gathered}
Q_{e}^{*}=F^{-1}\left(\frac{p_{e}-t_{e}+s_{e}-c-b_{e}}{p_{e}-t_{e}+s_{e}-v}\right) \\
Q_{r}^{*}=G^{-1}\left(\frac{p_{r}-t_{r}+s_{r}-w}{p_{r}-t_{r}+s_{r}}\right)
\end{gathered}
$$

\subsection{Online Channel Outsourcing Strategy}

Similarly to the independent inventory strategy, the manufacturer and the retailer make inventory decisions independently in their respective channels. The difference is that the manufacturer set up the online channel on the platform provided by the third party. The order fulfillment, inventory management, transportation and distribution of online channels are all outsourced to the third party (Figure 3). The manufacturer will pay $\theta$ to the third party platform for each unit of production sold.

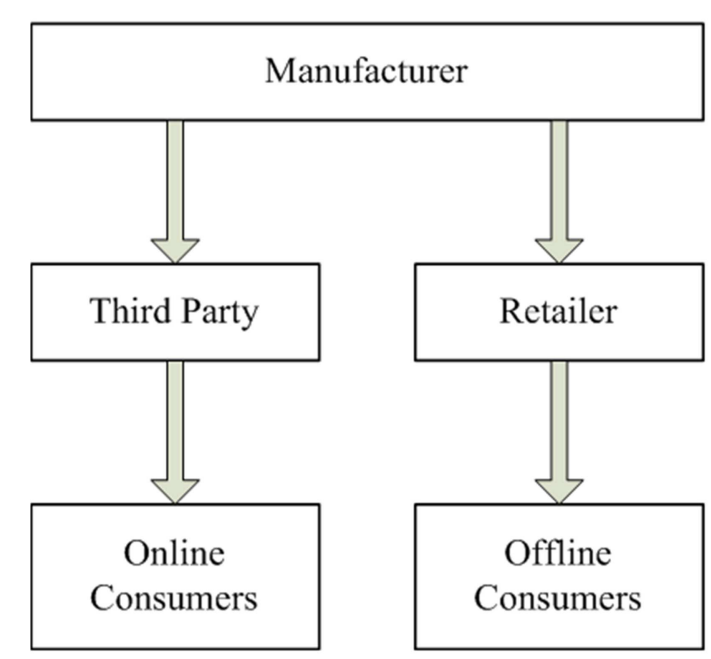

Figure 3. Online channel outsourcing strategy.

Under this strategy, the expected profits of manufacture and retailer are as follows: 


$$
\begin{aligned}
E\left[\pi_{e}^{3}\right] & =\left(p_{e}-\theta\right) \cdot E \min \left(Q_{e}, X\right)+w \cdot Q_{r}+v \cdot E \max \left(Q_{e}-X, 0\right)-c \cdot\left(Q_{e}+Q_{r}\right) \\
& -s_{e} \cdot E \max \left(X-Q_{e}, 0\right) \\
E\left[\pi_{r}^{3}\right] & =p_{r} \cdot E \min \left(Q_{r}, Y\right)+v \cdot E \max \left(Q_{r}-Y, 0\right)-w \cdot Q_{r}-\left(a_{r}+b_{r} \cdot Q_{r}\right) \\
& -s_{r} \cdot E \max \left(Y-Q_{r}, 0\right)
\end{aligned}
$$

The optimal order quantity for the manufacture is

$$
Q_{e}^{*}=F^{-1}\left(\frac{p_{e}+s_{e}-\theta-c}{p_{e}+s_{e}-\theta-v}\right)
$$

\section{Numerical Simulation Analysis}

In this section, the optimal inventory and the maximum

The offline channel will not be affected by the third party, so the optimal order quantity of the retailer is the same as the offline channel order quantity of independent inventory strategy. profit under different levels of demand uncertainty are studied through the numerical example.

According to the research literature [14, 15], the demand

\begin{tabular}{|c|c|c|c|c|c|c|c|c|c|c|c|c|c|c|}
\hline$\mu_{e}$ & $\mu_{r}$ & $p_{e}$ & $p_{r}$ & $w$ & $c$ & $t_{e}$ & $t_{r}$ & $v$ & $a_{e}$ & $a_{r}$ & $b_{e}$ & $\boldsymbol{b}_{\boldsymbol{r}}$ & $s_{e}$ & $s_{r}$ \\
\hline 300 & 300 & 9 & 10.5 & 4 & 2.5 & 0.4 & 1.2 & 1 & 30 & 40 & 0.4 & 0.6 & 1.2 & 1.6 \\
\hline
\end{tabular}
of the online channel and offline channel are normal distribution: $X \sim\left(300, \sigma_{e}^{2}\right), \mathrm{Y} \sim\left(300, \sigma_{r}^{2}\right)$. Table 2 lists the other parameters that were used in the numerical example.

Table 2. Values of the parameters.

The following (Figure 4, Figure 5, Figure 6) the analysis of the optimal order quantity and maximum profit of the manufacturer and the retailer at different variance levels under different inventory strategies.

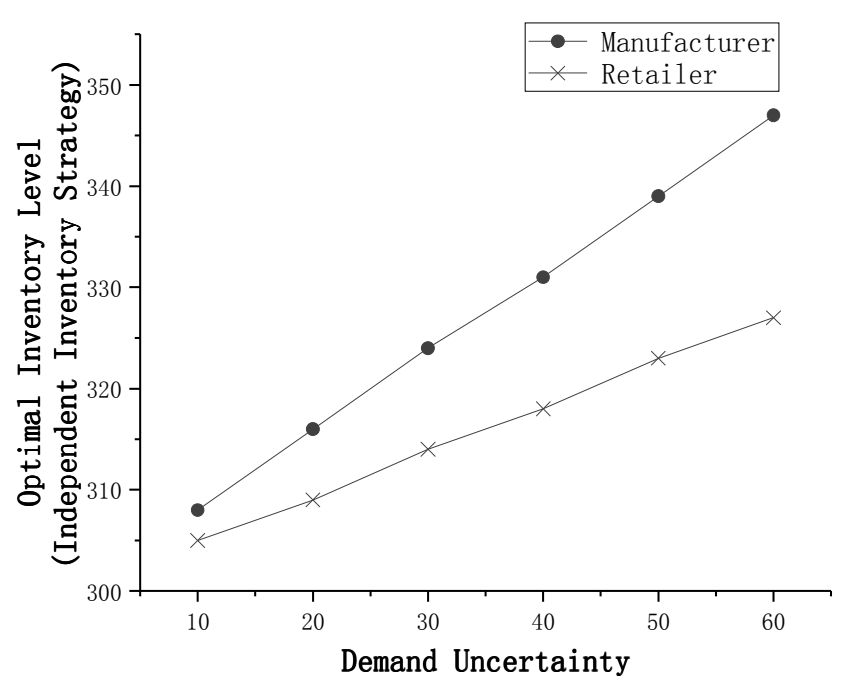

Figure 4. Relation between demand uncertainty and optimal order quantity.

The manufacturer and the retailer's optimal order quantity is increased with the increase of the uncertainty of market demand. To prevent cannot meet the demand of market and the shortage loss, they need more quantity of productions to ensure adequate inventory reserves. As can be seen from Figure 4, compared with the retailer, the manufacturer's optimal order quantity are more affected by the uncertainty of demand, which indicates that as a manufacturer, it needs to have a more accurate prediction of market demand.

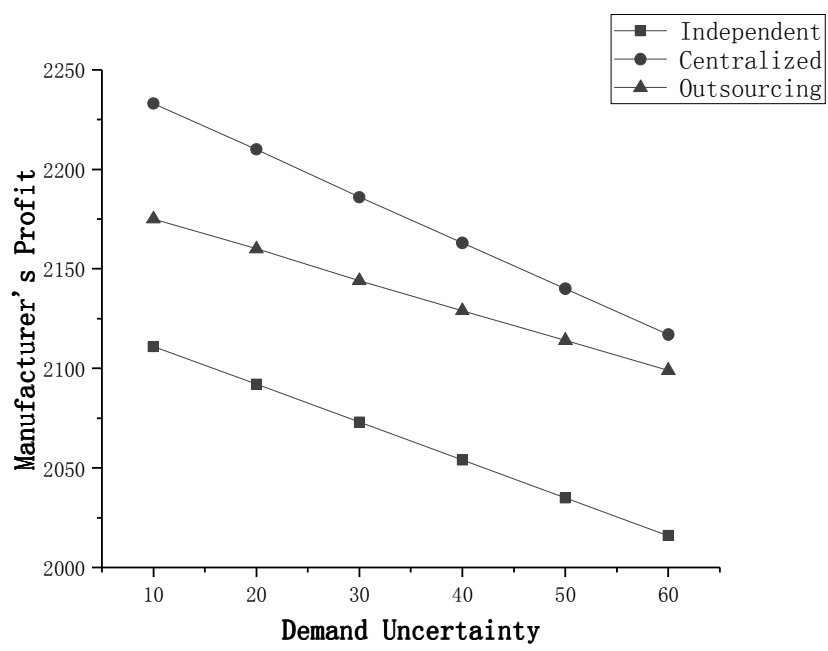

Figure 5. Relationship between demand uncertainty and manufacturer's profit.

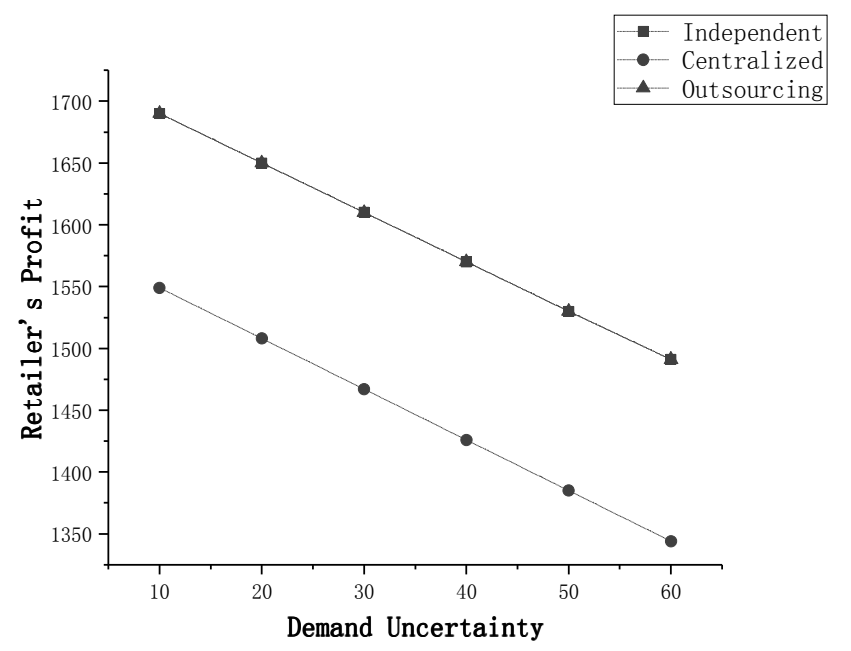

Figure 6. Relationship between demand uncertainty and retailer profit. 
It can be found from Figure 5 and Figure 6 that the uncertainty of market demand will lead to the prediction deviation of the manufacturer and the retailer. Improper orders can lead to overstocking or lack of inventory, thus reducing profit levels. To cope with changing demand, manufacturers and retailers tend to store more. The increase in inventory will also increase operating costs and reduce profits. In the same market demand environment, the profit of the manufacturer under centralized inventory strategy is higher than that under independent inventory strategy, while the profit of the retailer is opposite. This is because the retailer pays the manufacturer extra delivery costs under the centralized inventory strategy. As the core enterprise in the supply chain, the manufacturer should consider the overall interests of the supply chain comprehensively under the dual-channel centralized inventory strategy. The Manufacturer should establish a good relationship with the retailer to achieve a win-win result.

As for the manufacturer, the profit under the online channel outsourcing strategy is much higher than that under the independent inventory strategy. And with the increasing uncertainty of market demand, the profit of online channel outsourcing strategy also tends to be centralized inventory strategy. This is because online channel outsourcing disperses the channel risk caused by uncertain demand. The manufacturer outsource the online channel to a more professional third party can improve the market coverage of online channels. At the same time, the delivery speed and efficiency of the third party are higher, which make the online channel operate efficiently.

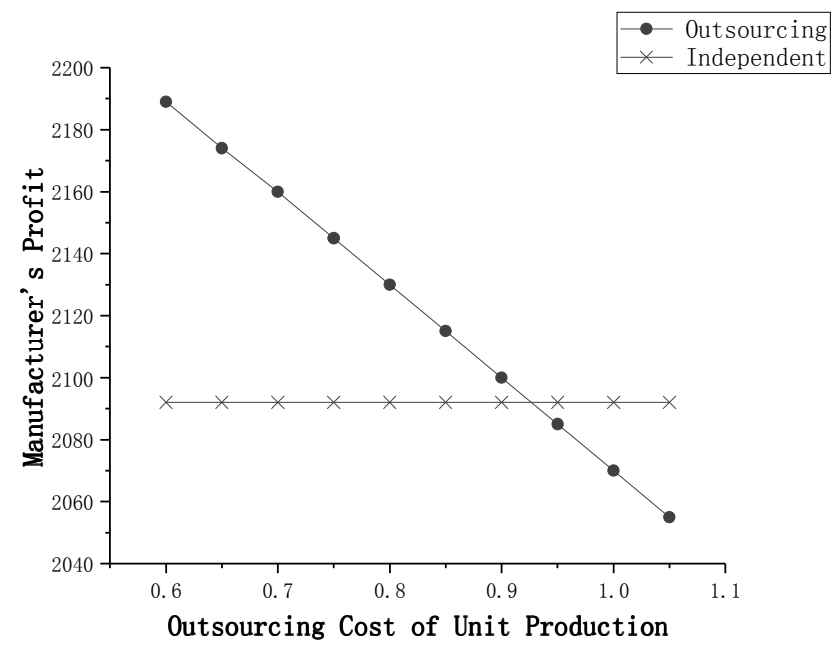

Figure 7. Relationship between outsourcing cost and manufacturer's profit.

Figure 7 shows the profit comparison between the manufacturer's independent inventory strategy and the online channel outsourcing strategy when $\sigma_{e}=20$. It can be seen that the profits of the manufacturer gradually decrease as the cost of unit production to be paid to the third party increases. When $\theta$ is about 0.9 , the maximum profit of outsourcing strategy is equal to the maximum profit of independent inventory strategy. When outsource the online channel, the manufacturer prefers the more professional and efficient online operation technologies and delivery services of the third party. The maximum profit is closely related to the outsourcing cost, and the appropriate cost makes the outsourcing strategy superior to operating the online channel independently.

\section{Conclusion}

Whether to expand online channels on the basis of original retail channels is one of the important decisions faced by core manufacturing enterprises in the supply chain. In theory, the dual channel supply chain structure can achieve better allocation of resources and reduce channel risk. However, the addition of a new channel means that manufacturers have to make decisions on the optimal inventory of each channel, and they also need to analyze and select multiple inventory strategies according to market conditions. This paper constructed three inventory strategies with dual channel structure, solved the optimal order quantity and maximum profit under different strategies, and analyzed the corresponding applicable conditions. Manufacturers should coordinate their relationships with retailers whatever the strategy. The enhancement of information sharing and the establishment of income contract are beneficial to the improvement of profits of both parties. In addition, when manufacturers outsource the online channels to the third party, it will fully exploit market and promote the efficiency of supply chain. This shows that the third party's choice assessment and price negotiations are particularly important.

\section{References}

[1] Hua G, Wang S, Chengc T C E. Price and lead time decisions in dual-channel supply chains [J]. European Journal of Operational Research, 2010, 205(1):113-126.

[2] Ryan J K, Sun D, Zhao X. Coordinating a Supply Chain With a Manufacturer-Owned Online Channel: A Dual Channel Model Under Price Competition [J]. IEEE Transactions on Engineering Management, 2013, 60(2):247-259.

[3] Li B, Chen P, Li Q, et al. Dual-channel supply chain pricing decisions with a risk-averse retailer [J]. International Journal of Production Research, 2014, 52(23):7132-7147.

[4] Tsay A A, Agrawal N. Channel Conflict and Coordination in the E-Commerce Age [J]. Production \& Operations Management, 2010, 13(1):93-110.

[5] Mukhopadhyay S K, Zhu X, Yue X. Optimal Contract Design for Mixed Channels Under Information Asymmetry [J]. Production \& Operations Management, 2010, 17(6):641-650.

[6] Dumrongsiri A. A supply chain model with direct and retail channels [J]. European Journal of Operational Research, 2008, 187(3):691-718.

[7] Chiangab W Y K. Managing inventories in a two-echelon dual-channel supply chain [J]. European Journal of Operational Research, 2005, 162(2):325-341.

[8] Geng Q, Mallik S. Inventory competition and allocation in a multi-channel distribution system [J]. European Journal of Operational Research, 2007, 182(2):704-729. 
[9] Yao D Q, Yue X, Mukhopadhyay S K, et al. Strategic inventory deployment for retail and e-tail stores [J]. Omega, 2009, 37(3):646-658.

[10] Takahashi K, Aoi T, Hirotani D, et al. Inventory control in a two-echelon dual-channel supply chain with setup of production and delivery $[\mathrm{J}]$. International Journal of Production Economics, 2011, 133(1):403-415.

[11] Bendolya E, Bretthauer K M, Venkataramanan M A. Service and cost benefits through clicks-and-mortar integration: Implications for the centralization/decentralization debate $[\mathrm{J}]$. European Journal of Operational Research, 2007, 180(1):426-442.
[12] Chen J, Zhang H, Sun Y. Implementing coordination contracts in a manufacturer Stackelberg dual-channel supply chain $[\mathrm{J}]$. Omega, 2012, 40(5):571-583.

[13] Xu minli, nie xiaozhe, Jane huiyun. Pricing decisions of dual-channel supply chain under different risk preferences [J]. Control and decision-making, 2016, 31(1):91-98.

[14] Xu qi, liu zheng, tang zhaoyong. Inventory coordination and cooperation strategy for dual-channel supply chain [J]. Systems engineering, 2015(3):45-51.

[15] Li jingquan, man xiufang. Research on retail multi-channel inventory strategy [J]. Business research, 2014, 56(11):28-33. 